\title{
Linking a role of IncRNAs (long non-coding RNAs) with insulin resistance, accelerated senescence, and inflammation in patients with type 2 diabetes
}

Chandrakumar Sathishkumar, Paramasivam Prabu, Viswanathan Mohan and Muthuswamy Balasubramanyam*

\begin{abstract}
Background: Studying epigenetics is expected to provide precious information on how environmental factors contribute to type 2 diabetes mellitus (T2DM) at the genomic level. With the progress of the whole-genome resequencing efforts, it is now known that $75-90 \%$ of the human genome was transcribed to generate a series of long non-coding RNAs (IncRNAs). While IncRNAs are gaining widespread attention as potential and robust biomarkers in the genesis as well as progression of several disease states, their clinical relevance and regulatory mechanisms are yet to be explored in the field of metabolic disorders including diabetes. Despite the fact that Asian Indians are highly insulin resistant and more prone to develop T2DM and associated vascular complications, there is virtually lack of data on the role of IncRNAs in the clinical diabetes setting. Therefore, we sought to evaluate a panel of IncRNAs and senescence-inflammation signatures in peripheral blood mononuclear cells (PBMCs) from patients with type 2 diabetes (T2DM; $n=30$ ) compared to individuals with normal glucose tolerance (NGT; $n=32$ ).

Results: Compared to control subjects, expression levels of IncRNAs in PBMCs from type 2 diabetes patients showed significantly $(p<0.05)$ increased levels of HOTAIR, MEG3, LET, MALAT1, MIAT, CDKN2BAS1/ANRIL, XIST, PANDA, GAS5, Linc-p21, ENST00000550337.1, PLUTO, and NBR2. In contrast, IncRNA expression patterns of THRIL and SALRNA1 were significantly $(p<0.05)$ decreased in patients with T2DM compared to control subjects. At the transcriptional level, senescence markers (p53, p21, p16, and $\beta$-galactosidase), proinflammatory markers (TNF- $\alpha$, IL6, MCP1, and IL1- $\beta$ ), and epigenetic signature of histone deacetylase-3 (HDAC3) were significantly $(p<0.05)$ elevated in patients with type 2 diabetes compared to control subjects. Interestingly, mRNA expression of Sirt1 and telomere length were significantly $(p<0.05)$ decreased in patients with type 2 diabetes compared to control subjects. Majority of the altered IncRNAs were positively correlated with poor glycemic control, insulin resistance, transcriptional markers of senescence, inflammation, and HDAC3 and negatively correlated with telomere length. Logistic regression analysis revealed a significant association of altered IncRNA signatures with T2DM, but this association was lost after adjusting for insulin resistance (HOMA-IR) and senescence markers.
\end{abstract}

Conclusion: Our study provides a clinically relevant evidence for the association of altered IncRNAs with poor glycemic control, insulin resistance, accelerated cellular senescence, and inflammation.

Keywords: IncRNA, SASP, HDAC3, Type 2 diabetes, Insulin resistance, Inflammation

\footnotetext{
* Correspondence: balusignal@gmail.com

Department of Cell and Molecular Biology and Dr. Rema Mohan High-Throughput Screening (HTS) Lab, Madras Diabetes Research Foundation and Dr. Mohan's Diabetes Specialties Centre, Gopalapuram, Chennai 600 086, India
}

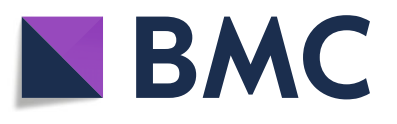

(c) The Author(s). 2018 Open Access This article is distributed under the terms of the Creative Commons Attribution 4.0 International License (http://creativecommons.org/licenses/by/4.0/), which permits unrestricted use, distribution, and reproduction in any medium, provided you give appropriate credit to the original author(s) and the source, provide a link to the Creative Commons license, and indicate if changes were made. The Creative Commons Public Domain Dedication waiver (http://creativecommons.org/publicdomain/zero/1.0/) applies to the data made available in this article, unless otherwise stated. 


\section{Introduction}

According to the latest edition of International Diabetes Federation Atlas [1], around 425 million people worldwide have diabetes and India alone harbors more than 73 millions of people with diabetes. While more than $90 \%$ of the diabetic population is affected majorly by type 2 diabetes mellitus (T2DM), it is a complex multi-factorial disease involving genetic, epigenetic, and environmental components. Several studies imply that accelerated aging, cellular senescence, and proinflammation are closely linked to the etiology of type 2 diabetes and insulin resistance $[2,3]$. Although the association between the proinflammation and senescence in the development of insulin resistance and type 2 diabetes is well known, the underlying molecular mechanisms and upstream regulatory networks are only poorly understood. Epigenetics appears to play a major role in the regulation of inflammation and cellular senescence-the dual pathological features commonly associated with type 2 diabetes [4]. Aberrant epigenetic modifications such as DNA methylation, histone modification, and non-coding RNA alterations are well-recognized drivers for the cancer phenotype, but the accumulating evidence also implies their role in the etiology of diabetes and cardiovascular diseases.

Of the total genome that is transcribed, only $2 \%$ codes for proteins, whereas the vast majority of it is transcribed as non-coding RNAs which include long non-coding RNAs (lncRNAs), microRNAs, and others [5]. Of late, lncRNAs have gradually come into the spotlight for the increased appreciation of their functional importance both in health and disease [6]. IncRNAs were also found next to protein-coding genes that are under tight transcriptional control, and often, their expression pattern correlates with tissue differentiation, development, and disease [7]. The widespread dysregulation of IncRNA expression in several disease states and the finding that many lncRNAs are enriched for SNPs that associate with human traits/diseases have highlighted their role as master regulators $[8,9]$. Challenging the concept that protein-coding genes are the sole contributors to the development of human disease, recent studies emphasize that lncRNAs mediate disease pathogenesis and hence should be studied and targeted for therapeutic benefits [10]. Accumulating literature on genetic, experimental, and epidemiological studies also highlights a growing list of lncRNAs that control glucose homeostasis and contribute to the pathogenesis of diabetes and its complications. Despite the fact that Asian Indians are highly insulin resistant [11] and more prone to develop T2DM and associated vascular complications [12], there is lack of data on the role of lncRNAs in the clinical diabetes setting and this is the rationale behind our study. Therefore, we planned to study the potential interactions among insulin resistance, cellular senescence, and proinflammation with a central focus on lncRNAs so as to better understand the clinical significance of these molecular perturbations in type 2 diabetes.

\section{Research design and methods}

Recruitment of the study subjects

Study participants with normal glucose tolerance (NGT; $n=32$ ) and patients with type 2 diabetes (T2DM; $n=30$ ) were recruited from Dr. Mohan's Diabetes Specialties Centre, Chennai, India, and from the ongoing epidemiological cohorts. The study was approved by the institutional ethics committee of the Madras Diabetes Research Foundation and conducted according to the principles of Declaration of Helsinki. Written informed consent was obtained from all the study participants prior to the start of the study. All the study participants were clinically well characterized into respective groups according to the World Health Organization (WHO) classification criteria. While all the diabetic patients were on oral hypoglycemic agent (OHA) treatment, $<10 \%$ were also on insulin, in addition to OHA.

\section{Anthropometric measurements}

Anthropometric measurements including weight, height, and waist circumference were obtained using standardized techniques. Height was noted down with a tape measured to the nearest centimeter. Weight was measured with traditional spring balance that was kept on a firm horizontal surface. Body mass index (BMI) was calculated using the formula: weight $(\mathrm{kg}) /$ height $\left(\mathrm{m}^{2}\right)$. Waist circumference was measured using a non-stretchable fiber measuring tape. Blood pressure was recorded from the right arm in a sitting position to the nearest $2 \mathrm{mmHg}$ with a mercury sphygmomanometer (Diamond Deluxe BP apparatus, Pune, India). Two readings were taken $5 \mathrm{~min}$ apart, and the mean of the two readings was represented as the blood pressure.

\section{Biochemical and clinical investigations}

Fasting plasma glucose (glucose oxidase-peroxidase method), serum cholesterol (cholesterol oxidase-peroxidase-amidopyrine method), serum triglycerides (glycerol phosphate oxidase-peroxidase-amidopyrine method), and HDL cholesterol (direct method-polyethylene glycol-pretreated enzymes) were measured using Hitachi-912 Autoanalyser (Hitachi, Mannheim, Germany). The intra and inter assay co-efficient of variation for the biochemical assays was $<5 \%$. Low-density lipoprotein (LDL) cholesterol was calculated using the Friedewald formula [13]. Glycated hemoglobin (HbAlc) was estimated by high-pressure liquid chromatography using the variant analyzer (Bio-Rad, Hercules, Calif., USA). Serum insulin was estimated using enzyme-linked immunosorbent assay (Calbiotech, CA). Insulin resistance was calculated using the homeostasis 
assessment model (HOMA-IR) using the formula: fasting insulin $(\mu \mathrm{IU} / \mathrm{mL}) \times$ fasting glucose $(\mathrm{mmol} / \mathrm{L}) / 22.5$.

\section{Blood collection and isolation of peripheral blood mononuclear cells (PBMCs)}

Fasting blood (5-8 mL) was collected into the vacutainer tube and processed immediately for cell isolation within $2 \mathrm{~h}$ from the time of collection. Blood was processed for peripheral blood mononuclear cell (PBMC) isolation using Histopaque-1077 (Sigma-Aldrich) according to the standard protocol by overlaying the blood on density gradient solution and centrifugation at 1500-1800 rpm for $30 \mathrm{~min}$. The buffy coat layer containing the PBMCs was aspirated, washed thrice with phosphate-buffered saline (PBS; $\mathrm{pH}$ 7.2-7.4), and aliquoted for various experiments.

\section{RNA extraction and CDNA synthesis}

Total RNA was extracted using TRIzol reagent (Invitrogen) according to the manufacturer's protocol. RNA quantity and quality were assessed by NanoDrop 2000 (Thermo Scientific) instrument. For the first-strand cDNA synthesis reaction, total RNA $(1 \mu \mathrm{g})$ was adjusted with nuclease-free water and mixed with the cDNA synthesis master mix containing 100 units of RevertAid M-MuLV reverse transcriptase enzyme and $2 \times$ buffer, random hexamer primers $(1 \times), 20$ units of RNase inhibitor, and $10 \mathrm{mM}$ dNTP solution mix. The resultant samples were incubated at $42{ }^{\circ} \mathrm{C}$ for $60 \mathrm{~min}$ for the first-strand cDNA synthesis followed by a 5 -min incubation at $95{ }^{\circ} \mathrm{C}$ for enzyme deactivation. cDNA reaction negative control without reverse transcriptase enzyme (-RT) was also performed.

\section{IncRNA/mRNA expression by Q-PCR}

A panel of lncRNAs was chosen for this study based on their involvement in metabolic disorders as well as their emerging roles in senescence $[14,15]$. The relative expression of the lncRNA/mRNA signatures were analyzed by preparing reaction mixer with FastStart Universal SYBR Green Master (Roche) and the corresponding gene-specific primers (Sigma) with diluted cDNA and final volume made up to $20 \mu \mathrm{L}$ using nuclease-free water. Quantification and analysis were carried out in LightCycler ${ }^{\bullet} 96$ real-time PCR System (Roche). The target gene expression was normalized to the house-keeping gene 18SrRNA (lncRNA) and $\beta$-actin (mRNA), and relative expression was determined using $2^{-\triangle \Delta C T}$ method. Non-template control (NTC) was also performed for each reaction assay plate.

\section{DNA isolation and measurement of telomere length}

For the measurement of telomere length, DNA was isolated from the whole blood by phenol-chloroform extraction and ethanol precipitation [16]. Relative telomere length was determined by real-time PCR approach as previously described by Cawthon [17] with a minor modification in the PCR temperature conditions. This method measures the factor by which the ratio of telomere repeat copy number to single-gene copy number differs between a sample and that of a reference DNA sample. PCR amplification was achieved using telomere $(\mathrm{T})$ and single copy gene, 36B4 (encodes acidic ribosomal phosphoprotein) primers (S), which serves as a quantitative control. The mean telomere repeat gene sequence $(\mathrm{T})$ to a reference single copy gene $(\mathrm{S})$ was represented as T/S ratio-a reflection of relative telomere length [3].

\section{Statistical analysis}

All data are represented as mean \pm standard error mean (SEM) unless otherwise mentioned as standard deviation (SD). Based on our pilot study on the expression levels of lncRNAs and using the SPSS software, the minimum sample size required for the study was calculated as 28 in each group considering the level of significance set at 0.05 and the statistical power at 0.90 . Comparison between groups was performed using the independent sample Student $t$ test with $p<0.05$ as the criterion for statistical significance. Pearson correlation analysis was done between variables and the risk factors. Binary logistic regression analysis was performed to show the association between lncRNAs (independent variable) and diabetes (dependent variable). All analyses were done using SPSS Statistics (version 20.0) and GraphPad Prism (version 6).

\section{Results}

Clinical and biochemical characteristics of the study groups

Clinical and biochemical characteristics of the study subjects are depicted in Table 1. BMI and waist circumference were slightly and significantly higher in patients with type 2 diabetes compared to control subjects. Patients with type 2 diabetes exhibited significantly $(p<0.001)$ increased fasting plasma glucose and HbA1c compared to the control subjects. T2DM patients were also hyperinsulinemic and insulin resistant as characterized by significantly elevated fasting insulin levels and HOMA-IR values, respectively. Blood pressure and lipid parameters did not differ significantly between the groups.

\section{Altered IncRNA signatures in T2DM}

Compared to control subjects, expression profiling of lncRNAs in PBMCs from type 2 diabetes patients showed significantly $(p<0.05)$ increased levels of HOTAIR, MEG3, LET, MALAT1, MIAT, CDKN2BAS1/ANRIL, XIST, PANDA, GAS5, Linc-p21, ENST00000550337.1, PLUTO, and NBR2 (Fig. 1). In contrast, lncRNA expression patterns of THRIL and SALRNA1 were significantly $(p<0.05)$ decreased in patients with T2DM compared to control subjects (Fig. 1). 
Table 1 Clinical and biochemical characterization of the study subjects

\begin{tabular}{|c|c|c|c|}
\hline Parameter & $\begin{array}{l}\text { Normal glucose } \\
\text { tolerance [NGT] } \\
(n=32)\end{array}$ & $\begin{array}{l}\text { Type } 2 \text { diabetes } \\
\text { mellitus [T2DM] } \\
(n=30)\end{array}$ & $p$ value \\
\hline Age (years) & $44 \pm 8$ & $46 \pm 8$ & 0.218 \\
\hline Gender_male (female) & $18(14)$ & $18(12)$ & - \\
\hline Body mass index $\left(\mathrm{kg} / \mathrm{m}^{2}\right)$ & $25 \pm 3.1$ & $27 \pm 4$ & 0.015 \\
\hline Waist circumference (cm) & $85 \pm 8$ & $94 \pm 9$ & $<0.001$ \\
\hline $\begin{array}{l}\text { Fasting plasma glucose } \\
(\mathrm{mg} / \mathrm{dL})\end{array}$ & $87 \pm 9$ & $136 \pm 24$ & $<0.001$ \\
\hline $\begin{array}{l}\text { Glycated hemoglobin- } \\
\text { HbA1c (\%) }\end{array}$ & $5.6 \pm 0.34$ & $8.1 \pm 1.9$ & $<0.001$ \\
\hline HOMA-IR & $1.8 \pm 0.8$ & $6.9 \pm 3$ & $<0.001$ \\
\hline Fasting insulin $(\mu \mathrm{U} \mathrm{U} / \mathrm{mL})$ & $8.6 \pm 3.5$ & $22 \pm 7.2$ & $<0.001$ \\
\hline $\begin{array}{l}\text { Systolic blood pressure } \\
(\mathrm{mmHg})\end{array}$ & $120 \pm 25$ & $131 \pm 21$ & 0.079 \\
\hline $\begin{array}{l}\text { Diastolic blood pressure } \\
(\mathrm{mmHg})\end{array}$ & $79 \pm 13$ & $80 \pm 8$ & 0.795 \\
\hline Total cholesterol (mg/dL) & $174 \pm 28$ & $169 \pm 37$ & 0.545 \\
\hline Serum triglycerides $(\mathrm{mg} / \mathrm{dL})$ & $132 \pm 71$ & $138 \pm 49$ & 0.737 \\
\hline HDL cholesterol (mg/dL) & $41 \pm 10$ & $39 \pm 7$ & 0.352 \\
\hline LDL cholesterol (mg/dL) & $107 \pm 21$ & $102 \pm 34$ & 0.568 \\
\hline VLDL & $27 \pm 14$ & $28 \pm 10$ & 0.732 \\
\hline
\end{tabular}

Data represented as mean \pm SD. Italicized value represents statistically significant compared to NGT

\section{Augmentation of HDAC3 and impaired Sirt1 expression in T2DM}

Transcriptional profiling revealed that mRNA expression of HDAC3 was significantly $(p<0.05)$ increased while the Sirt1 level was significantly $(p<0.05)$ decreased in

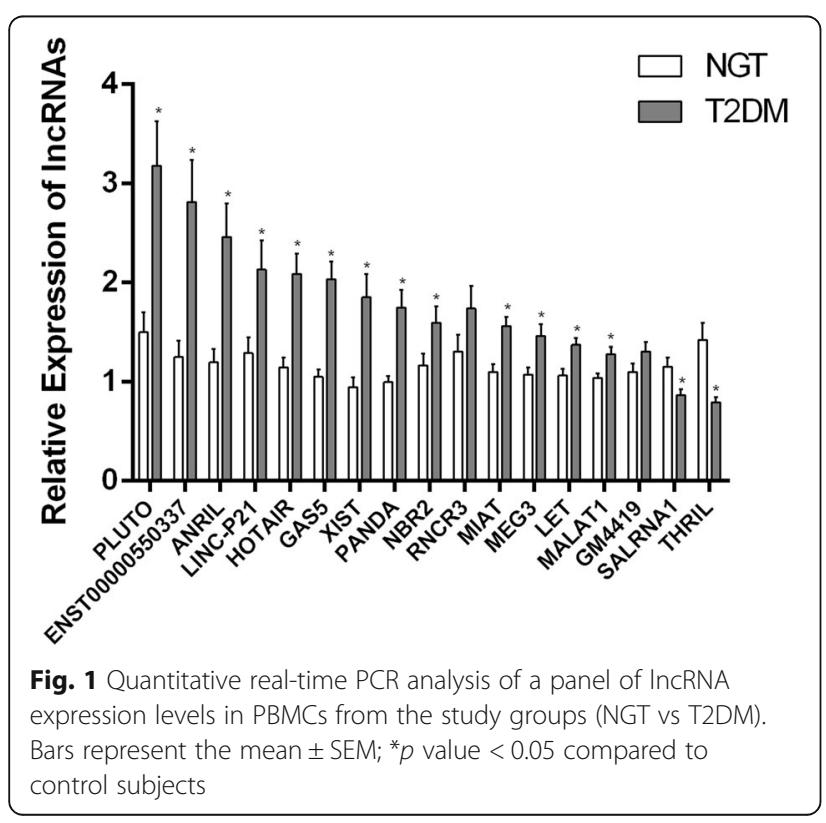

patients with type 2 diabetes compared to control subjects (Fig. 2).

\section{Altered senescence, inflammation, and telomere length in T2DM}

At the transcriptional level, senescence markers, viz., p53, p21, p16, and $\beta$-galactosidase 1 (GLB1), were significantly $(p<0.05)$ elevated in patients with type 2 diabetes compared to control subjects (Fig. 3a). As a final read-out of augmented cellular senescence, patients with T2DM were also characterized by significantly $(p<0.05)$ shortened telomeres compared to control subjects (Fig. 3b). Interestingly, mRNA expression levels of proinflammatory gene mediators, viz. TNF- $\alpha$, IL6, MCP1 and IL1- $\beta$, were also significantly upregulated $(p<0.05)$ in PBMCs from patients with type 2 diabetes, implying an acquisition state of senescence-associated secretory phenotype (Fig. 4).

\section{Correlation analysis}

A detailed correlation analysis of lncRNAs with various clinical and biochemical parameters (Additional file 1: Table S1) and molecular parameters (Additional file 2: Table S2) of the study subjects were summarized in the supplement tables. Majority of the altered lncRNAs were positively correlated with poor glycemic control, insulin resistance, transcriptional markers of senescence, inflammation, and HDAC3 and negatively correlated with telomere length. In contrast, expression levels of lncRNAs, viz., SALRNA1 and THRIL, were negatively correlated to glycemic control, insulin resistance, markers of senescence, inflammation, and HDAC3 and positively correlated to telomere length.

\section{Logistic regression analysis}

Logistic regression analysis using type 2 diabetes as dependent variable revealed that altered expression levels of lncRNAs, viz., PLUTO, ENST00000550337.1, CDKN2BAS1, LincRNA-P21, HOTAIR, GAS5, XIST, PANDA, NBR2, MIAT, MEG3, LET, MALAT1, SALRNA1, and THRIL, were associated significantly with T2DM, and this statistical significance was persisted even after adjusting for confounding factors like age and BMI. Interestingly, this statistical association was lost when adjusted for HOMA-IR and senescence markers. This implies that the association between lncRNAs and T2DM could be closely linked to insulin resistance and accelerated senescence with downstream inflammatory signaling (Table 2).

\section{Discussion}

Recent literature implies that the dysregulation of lncRNA expression and functionality contributes to several pathophysiological states as several lncRNAs get 


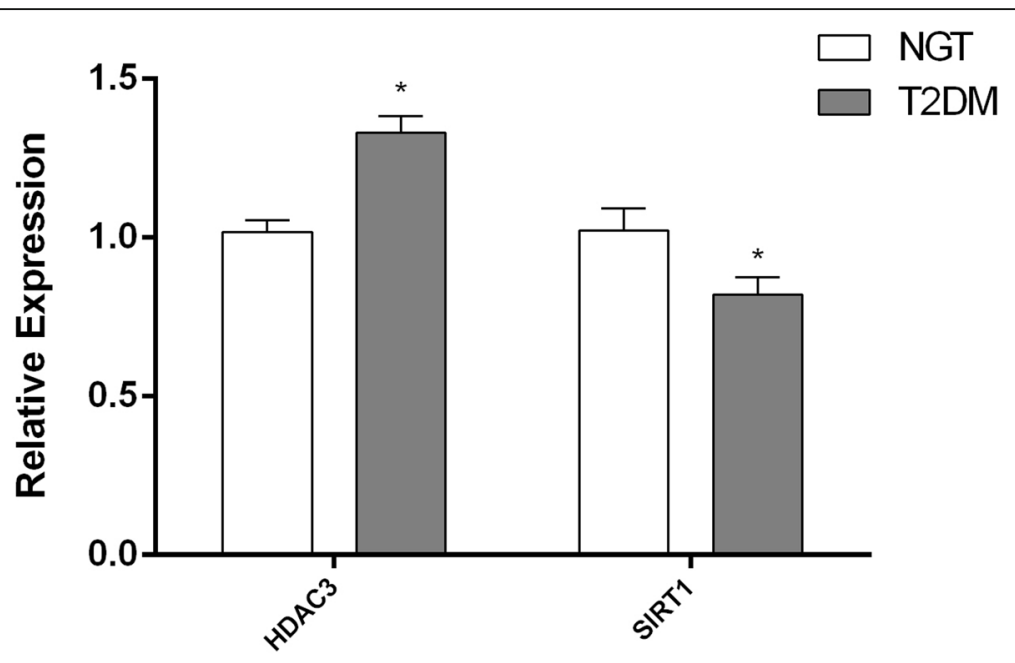

Fig. 2 Quantitative real-time PCR analysis of HDAC3 and SIRT1 in PBMCs from the study groups (NGT vs T2DM). Bars represent the mean \pm SEM; ${ }^{*} p$ value $<0.05$ compared to control subjects
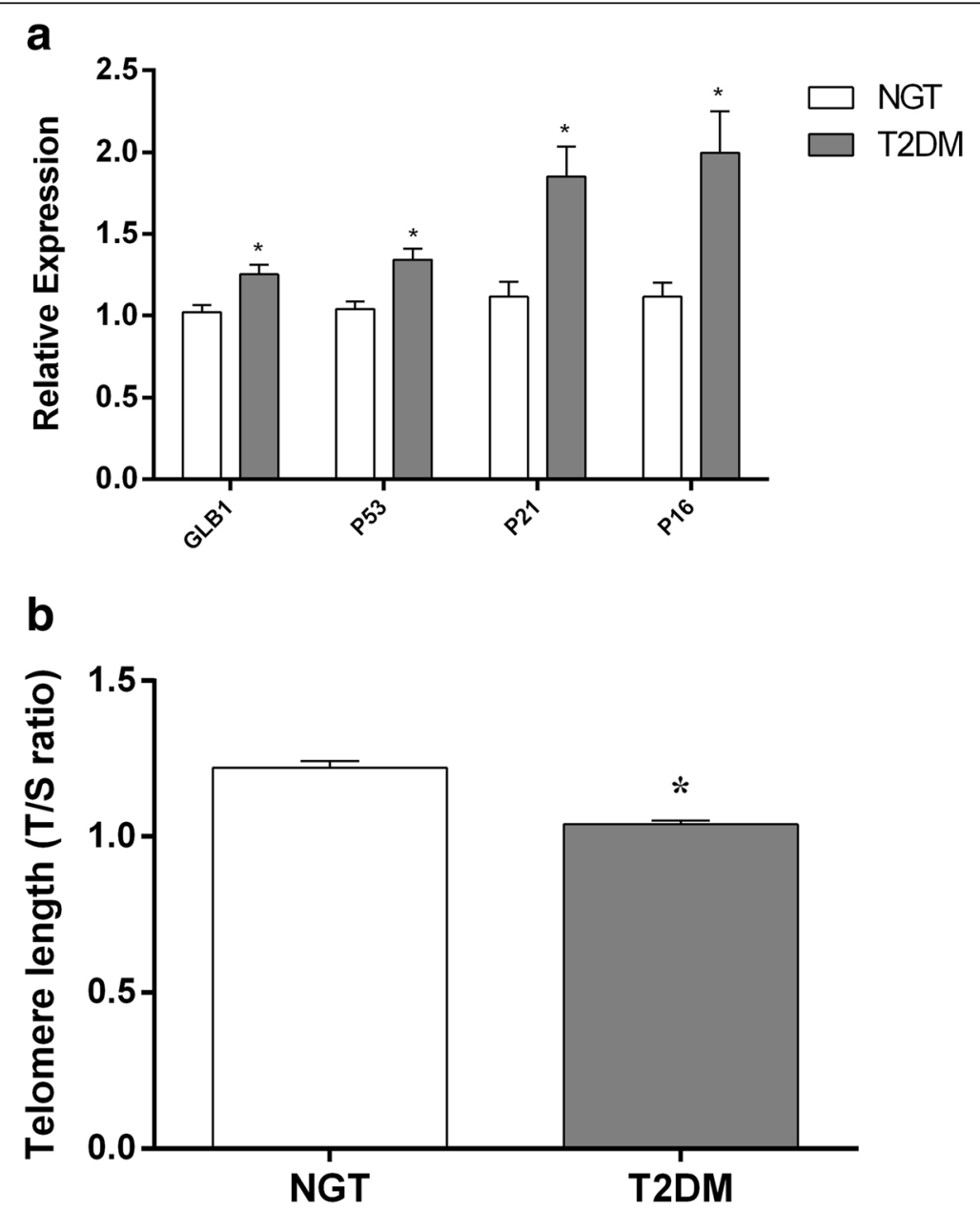

Fig. 3 Quantitative real-time PCR analysis of senescence marker gene expression levels, viz., GLB1, P53, P21, and P16 (a), and telomere length (b) in PBMCs from the study groups (NGT vs T2DM). Bars represent the mean \pm SEM; ${ }^{*} p$ value $<0.05$ compared to control subjects 


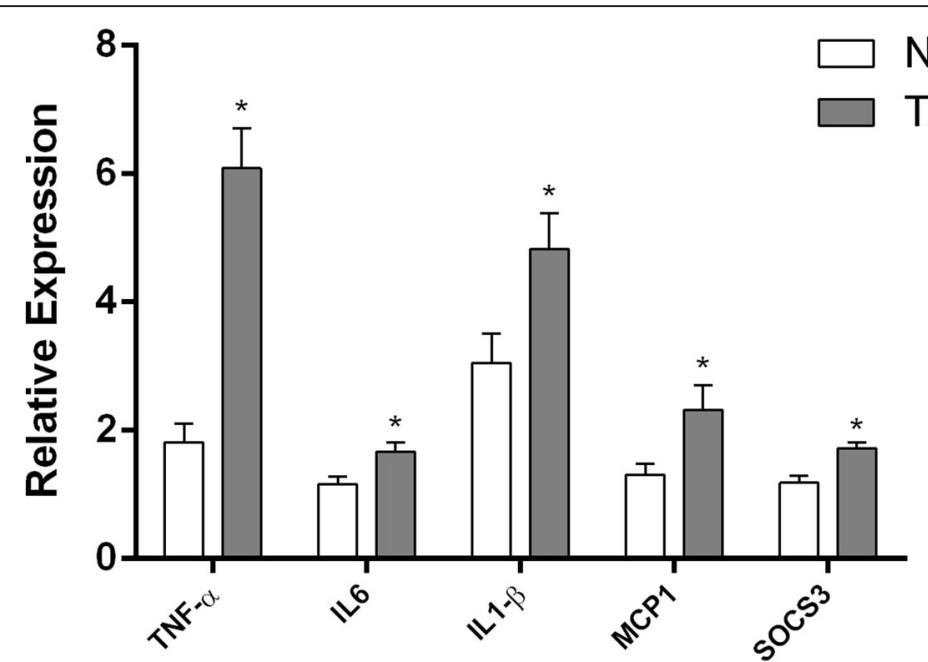

Fig. 4 Quantitative real-time PCR analysis of inflammatory signature gene expression levels, viz., TNFa, IL6, MCP1, IL1 $\beta$, and SOCS3 in PBMCs from the study groups (NGT vs T2DM). Bars represent the mean \pm SEM; ${ }^{*} p$ value $<0.05$ compared to control subjects

validated as bona fide prognostic/diagnostic markers and drug targets $[9,18,19]$. The role of IncRNAs in the pathogenesis of type 2 diabetes mellitus and related complications has only recently been recognized, but there is already some evidence for their involvement in many of the pathophysiological mechanisms that are linked to the genesis and progression of disease [20, 21]. Despite the fact that Asian Indians are highly insulin resistant [10], more prone to develop type 2 diabetes mellitus (T2DM) and associated vascular complications [11], and exhibit increased susceptibility to early $\beta$-cell dysfunction [22], there is virtually lack of data on the role of lncRNAs in the clinical diabetes setting. Our study is the first report from India to show an association of altered signatures of lncRNAs in T2DM with pathological connectivity reflected by poor glycemic control, insulin resistance, accelerated cellular senescence, and meta-inflammation.

Table 2 Binary logistic regression analysis using type 2 diabetes as dependent variable

\begin{tabular}{|c|c|c|c|c|c|c|c|c|c|c|}
\hline & \multicolumn{2}{|c|}{ Unadjusted } & \multicolumn{2}{|c|}{$\begin{array}{l}\text { Adjusted for age } \\
\text { and BMl }\end{array}$} & \multicolumn{2}{|c|}{$\begin{array}{l}\text { Adjusted for } \\
\text { HOMA-IR }\end{array}$} & \multicolumn{2}{|c|}{$\begin{array}{l}\text { Adjusted for senescence markers } \\
\text { (GLB, P53, P21, P16, and TL) }\end{array}$} & \multicolumn{2}{|c|}{$\begin{array}{l}\text { Adjusted for inflammatory markers } \\
\text { (TNF- } \alpha \text {, IL6, MCP1, IL1- } \beta \text {, and SOCS3) }\end{array}$} \\
\hline & $\bar{\beta}$ & $p$ & $\bar{\beta}$ & $p$ & $\bar{\beta}$ & $p$ & $\bar{\beta}$ & $p$ & $\beta$ & $p$ \\
\hline PLUTO & 1.721 & 0.005 & 1.827 & 0.003 & 23.673 & 0.063 & 1.848 & 0.210 & 2.204 & 0.025 \\
\hline ENST00000550337.1 & 2.023 & 0.004 & 1.925 & 0.013 & 2.984 & 0.132 & 33.73 & 0.184 & 4.026 & 0.038 \\
\hline CDKN2BAS1 & 3.173 & 0.006 & 4.925 & 0.002 & 4.188 & 0.068 & 2.741 & 0.100 & 2.995 & 0.044 \\
\hline lincRNA-p21 & 1.867 & 0.021 & 1.970 & 0.033 & 3.492 & 0.096 & 2.283 & 0.311 & 6.395 & 0.013 \\
\hline HOTAIR & 4.348 & 0.001 & 5.256 & 0.001 & 2.556 & 0.342 & 1.651 & 0.524 & 8.125 & 0.015 \\
\hline GAS5 & 10.642 & 0.001 & 14.054 & 0.001 & 20.820 & 0.226 & 22.512 & 0.128 & 12.214 & 0.069 \\
\hline XIST & 0.388 & 0.003 & 3.824 & 0.004 & 3.677 & 0.145 & 2.318 & 0.386 & 3.166 & 0.024 \\
\hline PANDA & 7.960 & 0.003 & 15.737 & 0.002 & 30.052 & 0.041 & 27.726 & 0.151 & 3.548 & 0.253 \\
\hline NBR2 & 2.045 & 0.041 & 1.728 & 0.159 & 1.496 & 0.522 & 1.869 & 0.443 & 2.675 & 0.141 \\
\hline RNCR3 & 1.464 & 0.144 & 1.650 & 0.065 & 1.795 & 0.394 & 1.582 & 0.410 & 1.740 & 0.225 \\
\hline MIAT & 6.591 & 0.002 & 5.293 & 0.012 & 8.383 & 0.235 & 8.753 & 0.181 & 5.388 & 0.118 \\
\hline MEG3 & 5.669 & 0.013 & 6.444 & 0.017 & 17.060 & 0.141 & 12.830 & 0.063 & 57.903 & 0.023 \\
\hline LET & 7.116 & 0.014 & 5.806 & 0.036 & 6.736 & 0.068 & 4.399 & 0.534 & 2.079 & 0.584 \\
\hline MALAT1 & 9.945 & 0.008 & 5.156 & 0.046 & 4.712 & 0.193 & 12.858 & 0.343 & 33.033 & 0.086 \\
\hline GM4419 & 2.468 & 0.104 & 2.142 & 0.242 & 3.254 & 0.232 & 4.832 & 0.293 & 1.937 & 0.433 \\
\hline SALRNA1 & 0.161 & 0.013 & 0.114 & 0.009 & 0.029 & 0.127 & 0.072 & 0.057 & 0.092 & 0.100 \\
\hline THRIL & 0.047 & 0.001 & 0.529 & 0.001 & 0.013 & 0.084 & 0.063 & 0.139 & 0.333 & 0.271 \\
\hline
\end{tabular}


Our study is in consistent with the recent literature of several IncRNAs upregulated in diabetes state. In support of our findings, increased expression of GAS5 [23] and IncRNA ENST00000550337.1 [24] was reported in type 2 diabetes even with high diagnostic claim and biomarker value. A role for IncRNAs XIST [25] and GM4419 [26] was implicated in diabetic nephropathy while alterations in PANDA [27] and NBR2 [28] P21 [29] were linked to cellular senescence, AMPK regulation, and liver fibrosis, respectively. Expression levels of IncRNA-LET was shown to be decreased in a certain type of cancers [30], but we observed it to be upregulated in patients with type 2 diabetes. MIAT is identified to be involved in various diseases, particularly myocardial infarction, diabetic retinopathy, and various other microvascular complications [31]. Similarly, lncRNA RNCR3 was shown to be increased in retinal vasculature of an animal model as well as in vitro cell model [32]. While lncRNA PLUTO has been shown to be downregulated in islets from donors who are patients with type 2 diabetes and pre-diabetes subjects [33], our study observed a highly significant upregulation of PLUTO in patients with type 2 diabetes. Previous studies also reported that upregulated expression of IncRNA MALAT1 was linked to hyperglycemia-induced inflammation and endothelial dysfunction [34], diabetic nephropathy [35], and gestational diabetes mellitus [36]. In vitro studies demonstrated that HOTAIR interacts with the various chromatin-modifying enzymes and thereby participates in the regulation of gene expression [37]. A functional role for HOTAIR in the diabetes pathogenesis is yet to be established; however, its role has been hinted to be associated with regional adiposity [38]. IncRNA MEG3 has an important regulatory role in beta cell function [39], and the knock-down of MEG3 has been shown contributing to the pathology of diabetic microvascular complication [40]. In contrast, MEG3 gene expression was shown upregulated in the hepatocytes from mice fed with high-fat diet as well as in ob/ob mice and this has been linked to increased hepatic gluconeogenesis [41].

Our study provides the first preliminary evidence that expression of the long non-coding RNAs, THRIL, and SALRNA1 were decreased in patients with type 2 diabetes and negatively correlated with hyperglycemia, senescence, and inflammation. THRIL was shown to regulate TNF- $\alpha$ expression through an epigenetic mechanism, and TNF- $\alpha$ can also reduce THRIL expression via a negative feedback action [42]. Similarly, SAL-RNA1 was earlier identified as putative agedelaying lncRNA, since its reduction with small inhibitory RNAs (siRNA) induced rapid aging changes of the fibroblasts, such as large cell morphology, positive $\beta$-galactosidase activity, and upregulation of p53 [43]. Notably, lncRNA ANRIL shown upregulated in our study was also linked to CDKN2A/B, a strong type 2 diabetes risk gene variant $[44,45]$.

It is interesting to note that the majority of differentially expressed lncRNAs in patients with type 2 diabetes observed in our study are involved in cell cycle regulation and senescence and their expression levels correlated to poor glycemic control, insulin resistance, accelerated senescence, and inflammation. Several lncRNAs were reported to influence the molecular processes that underlie age-associated phenotypes and play an important role in accelerated aging $[4,46]$. Type 2 diabetes has been linked to cellular senescence, senescence-associated secretory phenotype (SASP), and accelerated aging $[47,48]$, and our lab was the first one in the world literature to report an association of increased telomere shortening in patients with type 2 diabetes [2, 3]. Earlier, we have also shown increased HDAC3 epigenetic signature in patients with type 2 diabetes [49], and in the present study, there was a positive correlation of HDAC3 mRNA expression with majority of the lncRNAs and this endorses the concerted and coordinated interactions between IncRNAs and histone modifications [50].

Our work offers an avenue for several translational applications including a role of lncRNAs in lifestyle changes. Recent findings suggest a putative role of non-coding RNAs in physical activity and several miRNAs have been identified as modulators of exercise-induced adaption at both systemic and tissue levels [51]. Contrast to miRNAs, little is known about the role of long non-coding RNAs (lncRNAs) in exercise. Identification of the role of lncRNAs in exercise will improve our understanding of exercise physiology and has the potential to enhance the application of current therapeutic approaches. In fact, a micropeptide encoded by a putative IncRNA has been shown to regulate muscle performance [52]. Although very little is known about the relationship between lncRNAs and dietary factors, it appears that dietary manipulation could also beneficially alter the expression of lncRNAs and thereby ensure health [53].

One of the limitations of our study is of its cross-sectional nature as well as small sample size, and hence, the findings of the study and its conclusions should be interpreted with caution. From this pilot study, we could not extrapolate causal link of alterations in lncRNAs with type 2 diabetes, and it needs replication and prospective follow-up studies. Secondly, considering the tissue-specific and heterogeneous actions of lncRNAs, the alterations seen in PBMCs might only mirror disease-pathology directionality. However, the altered expression profile of IncRNAs in PBMCs has been shown to reflect the pathophysiology in different disease states including multiple sclerosis [54], myocardial infarction [55], and rheumatoid arthritis [56]. In fact, a recent study of deep RNA sequencing uncovered a repertoire 
of human macrophage lncRNAs modulated by macrophage activation and closely linked it to the pathophysiology of cardiometabolic diseases [57].

\section{Conclusion}

To conclude, our study is of its first kind in India to report altered lncRNA profiles linked to poor glycemic control, insulin resistance, senescence, and proinflammation in patients with type 2 diabetes. A better understanding of the mechanisms underlying the functions of IncRNAs will help us to understand the ever-expanding pathophysiology of diabetes and its complications and thereby adapt to prevention strategies as well as to develop novel therapeutic agents.

\section{Additional files}

Additional file 1: Table S1. Correlation analysis of LncRNAs with clinical and biochemical parameters. (DOCX $21 \mathrm{~kb}$ )

Additional file 2: Table S2. Correlation analysis of LncRNAs with molecular parameters. (DOCX $18 \mathrm{~kb})$

\section{Abbreviations}

BMI: Body mass index; GLB1: $\beta$-Galactosidase 1; HbA1C: Glycated hemoglobin; HDAC: Histone deacetylase; HOMA-IR: Homeostatic model assessment-insulin resistance; IL-1 B: Interleukin-1 beta; IL-6: Interleukin-6; IncRNAs: Long non-coding RNAs; MCP-1: Monocyte chemoattractant protein 1; NFkB: Nuclear factor kappa-light-chain-enhancer of activated B cells; NGT: Normal glucose tolerance; P16: Cyclin-dependent kinase inhibitor 2A; P21: Cyclin-dependent kinase inhibitor 1A; P53: Tumor protein/tumor suppressor 53; PBMCs: Peripheral blood mononuclear cells; SASP: Senescenceassociated secretory phenotype; Sirt1: Sirtuin (silent mating-type information regulation 2 homolog) 1: SOCS-3: Suppressor of cytokine signaling 3: T2DM: Type 2 diabetes mellitus; TNF-a: Tumor necrosis factor-a

\section{Funding}

The authors acknowledge research grant support from the Department of Biotechnology (DBT), New Delhi, and the Indian Council of Medical Research (ICMR), Govt. of India and senior research fellowship assistance from the Council of Scientific and Industrial Research (CSIR), New Delhi, India.

\section{Availability of data and materials}

The authors consent to the availability of data and materials. The datasets used and/or analyzed during the current study are available from the corresponding author on reasonable request.

\section{Authors' contributions}

MB conceived, designed, supervised, and commented on all drafts of this paper. CS and PP coordinated the clinical sample collection, conducted the overall experiments, and participated in the data collection and analysis and molecular investigations and helped in the drafts. VM and MB contributed to the data interpretation and manuscript completion. All authors read and approved the final manuscript.

\section{Ethics approval and consent to participate}

The study was approved by the institutional ethics committee of the Madras Diabetes Research Foundation and conducted according to the principles of Declaration of Helsinki. Written informed consent was obtained from all the study participants prior to the start of the study.

\section{Consent for publication}

Institutional consent form is inclusive of data protection and consent for research publication.

All the authors approved the manuscript and consented for publication.

\section{Competing interests}

The authors declare that they have no competing interests.

\section{Publisher's Note}

Springer Nature remains neutral with regard to jurisdictional claims in published maps and institutional affiliations.

Received: 10 April 2018 Accepted: 13 August 2018

Published online: 23 August 2018

\section{References}

1. International Diabetes Federation. IDF diabetes atlas. 8th ed. Brussels: International Diabetes Federation; 2017.

2. Adaikalakoteswari A, Balasubramanyam M, Mohan V. Telomere shortening occurs in Asian Indian type 2 diabetic patients. Diabet Med. 2005;22:1151-6.

3. Monickaraj F, Aravind S, Gokulakrishnan K, Sathishkumar C, Prabu P, Prabu D, Mohan V, Balasubramanyam M. Accelerated aging as evidenced by increased telomere shortening and mitochondrial DNA depletion in patients with type 2 diabetes. Mol Cell Biochem. 2012;365:343-50.

4. Grammatikakis I, Panda AC, Abdelmohsen K, Gorospe M. Long noncoding RNAs (IncRNAs) and the molecular hallmarks of aging. Aging. 2014;6: 992-1009.

5. Hangauer MJ, Vaughn IW, McManus MT. Pervasive transcription of the human genome produces thousands of previously unidentified long intergenic noncoding RNAs. PLoS Genet. 2013;9:e1003569.

6. Morris KV, Mattick JS. The rise of regulatory RNA. Nat Rev Genet. 2014;15: 423-37.

7. Batista PJ, Chang HY. Long noncoding RNAs: cellular address codes in development and disease. Cell. 2013:152:1298-307.

8. Du Z, Fei T, Verhaak RGW, Su Z, Zhang Y, Brown M, Chen Y, Liu SX. Integrative genomic analyses reveal clinically relevant long noncoding RNAs in human cancer. Nat Struct Mol Biol. 2013;20:908-13.

9. Jain S, Thakkar N, Chhatai J, Bhadra M, Bhadra U. Long non-coding RNA: functional agent for disease traits. RNA Biol. 2016;14:1-14.

10. DiStefano JK. The emerging role of long noncoding RNAs in human disease. Methods Mol Biol. 2018;1706:91-110.

11. Sharp PS, Mohan V, Levy JC, Mather HM, Kohner EM. Insulin resistance in patients of Asian Indian and European origin with non-insulin dependent diabetes. Horm Metab Res. 1987;19:84-5.

12. Unnikrishnan R, Pradeepa R, Joshi SR, Mohan V. Type 2 diabetes: demystifying the global epidemic. Diabetes. 2017;66:1432-42.

13. Friedewald WT, Levy Rl, Fredrickson DS. Estimation of the concentration of low-density lipoprotein cholesterol in plasma, without use of the preparative ultracentrifuge. Clin Chem. 1972;18:499-502.

14. Montes M, Lund AH. Emerging roles of IncRNAs in senescence. FEBS J. 2016; 283:2414-26.

15. Kim C, Kang D, Lee EK, Lee JS. Long noncoding RNAs and RNA-binding proteins in oxidative stress, cellular senescence, and age-related diseases. Oxidative Med Cell Longev. 2017;2017:2062384.

16. Köchl S, Niederstätter H, Parson W. DNA extraction and quantitation of forensic samples using the phenol-chloroform method and real-time PCR. Methods Mol Biol. 2005;297:13-30.

17. Cawthon RM. Telomere measurement by quantitative PCR. Nucleic Acids Res. 2002;30:e4730.

18. Matsui M, Corey DR. Non-coding RNAs as drug targets. Nat Rev Drug Discov. 2017;16:167-79.

19. Ghanbari M, Peters MJ, de Vries PS, Boer CG, van Rooij JGJ, Lee YC, Kumar V, Uitterlinden AG, Ikram MA, Wijmenga C, et al. A systematic analysis highlights multiple long non-coding RNAs associated with cardiometabolic disorders. J Hum Genet. 2018:63:431-46.

20. Leti F, DiStefano JK. Long noncoding RNAs as diagnostic and therapeutic targets in type 2 diabetes and related complications. Genes (Basel). 2017;22:8.

21. Goyal N, Kesharwani D, Datta M. Lnc-ing non-coding RNAs with metabolism and diabetes: roles of IncRNAs. Cell Mol Life Sci. 2018;75:1827-37.

22. Mohan V, Amutha A, Ranjani H, Unnikrishnan R, Datta M, Anjana R, Staimez L, Ali MK, Narayan VKM. Associations of $\beta$-cell function and insulin resistance with youth-onset type 2 diabetes and prediabetes among Asian Indians. Diabetes Technol Ther. 2013;15:315-22. 
23. Carter G, Miladinovic B, Patel AA, Deland L, Mastorides S, Patel NA. Circulating long noncoding RNA GAS5 levels are correlated to prevalence of type 2 diabetes mellitus. BBA Clinical. 2015;4:102-7.

24. Li X, Zhao Z, Gao C, Rao L, Hao P, Jian D, Li W, Tang H, Li M. The diagnostic value of whole blood IncRNA ENST00000550337.1 for pre-diabetes and type 2 diabetes mellitus. Exp Clin Endocrinol Diabetes. 2017;125:377-83.

25. Huang $\mathrm{Y}-\mathrm{S}$, Hsieh H-Y, Shih H-M, Sytwu H-K, Wu C-C. Urinary Xist is a potential biomarker for membranous nephropathy. Biochem Biophys Res Commun. 2014:452:415-21.

26. Yi H, Peng R, L-y Z, Sun Y, H-m P, H-d L, Yu L-j, A-I L, Y-j Z, W-h J, et al. LincRNA-Gm4419 knockdown ameliorates NF-kB/NLRP3 inflammasomemediated inflammation in diabetic nephropathy. Cell Death Dis. 2017;8:e2583.

27. Puvvula P, Desetty R, Pineau P, Marchio A, Moon A, Dejean A, Bischof O. Long noncoding RNA PANDA and scaffold-attachment-factor SAFA control senescence entry and exit. Nat Commun. 2014:5:5323.

28. Liu X, Gan B. IncRNA NBR2 modulates cancer cell sensitivity to phenformin through GLUT1. Cell Cycle. 2016;15:3471-81.

29. Yu F, Lu Z, Chen B, Dong P, Zheng J. Identification of a novel lincRNA-p21miR-181b-PTEN signaling cascade in liver fibrosis. Mediat Inflamm. 2016; 2016:9856538

30. Sun Q, Liu H, Li L, Zhang S, Liu K, Liu Y, Yang C. Long noncoding RNA-LET, which is repressed by $\mathrm{EZH} 2$, inhibits cell proliferation and induces apoptosis of nasopharyngeal carcinoma cell. Med Oncol. 2015;32:226.

31. Liao J, He Q, Li M, Chen Y, Liu Y, Wang J. LncRNA MIAT: myocardial infarction associated and more. Gene. 2015;578:158-61.

32. Shan K, Jiang Q, Wang QX, Wang NY, Yang H, Yao DM, Liu C, Li MX, Yao J, Liu $B$, et al. Role of long non-coding RNA-RNCR3 in atherosclerosis-related vascular dysfunction. Cell Death Dis. 2016;7:e2248.

33. Akerman I, Tu Z, Beucher A, Rolando D, Sauty-Colace C, Benazra M, Nakic N, Yang J, Wang $H$, Pasquali L, et al. Human pancreatic $\beta$ cell IncRNAs control cell-specific regulatory networks. Cell Metab. 2017;25:400-11.

34. Puthanveetil P, Chen S, Feng B, Gautam A, Chakrabarti S. Long non-coding RNA MALAT1 regulates hyperglycaemia induced inflammatory process in the endothelial cells. J Cell Mol Med. 2015;19:1418-25.

35. Li X, Zeng L, Cao C, Lu C, Lian W, Han J, Zhang X, Zhang J, Tang T, Li M. Long noncoding RNA MALAT1 regulates renal tubular epithelial pyroptosis by modulated miR-23c targeting of ELAVL1 in diabetic nephropathy. Exp Cell Res. 2017;350:327-35.

36. Zhang Y, Wu H, Wang F, Ye M, Zhu H, Bu S. Long non-coding RNA MALAT1 expression in patients with gestational diabetes mellitus. Int J Gynecol Obstet. 2018;140:164-9.

37. Gupta RA, Shah N, Wang KC, Kim J, Horlings HM, Wong DJ, Tsai M-C, Hung T, Argani P, Rinn JL, et al. Long non-coding RNA HOTAIR reprograms chromatin state to promote cancer metastasis. Nature. 2010;464:1071-6.

38. Divoux A, Karastergiou K, Xie H, Guo W, Perera RJ, Fried SK, Smith SR. Identification of a novel IncRNA in gluteal adipose tissue and evidence for its positive effect on preadipocyte differentiation. Obesity. 2014;22:1781-5.

39. You L, Wang N, Yin D, Wang L, Jin F, Zhu Y, Yuan Q, De W. Downregulation of long noncoding RNA Meg3 affects insulin synthesis and secretion in mouse pancreatic beta cells. J Cell Physiol. 2016;231:852-62.

40. Qiu G-Z, Tian W, Fu H-T, Li C-P, Liu B. Long noncoding RNA-MEG3 is involved in diabetes mellitus-related microvascular dysfunction. Biochem Biophys Res Commun. 2016:471:135-41.

41. Zhu X, Wu Y-B, Zhou J, Kang D-M. Upregulation of IncRNA MEG3 promotes hepatic insulin resistance via increasing FoxO1 expression. Biochem Biophys Res Commun. 2016;469:319-25

42. Li Z, Chao T-C, Chang K-Y, Lin N, Patil VS, Shimizu C, Head SR, Burns JC, Rana TM. The long noncoding RNA THRIL regulates TNFa expression through its interaction with hnRNPL. Proc Natl Acad Sci. 2014;111:1002-7.

43. Abdelmohsen K, Panda A, Kang MJ, Xu J, Selimyan R, Yoon JH, Martindale J, De S, Wood WH, Becker KG, et al. Senescence-associated IncRNAs: senescence-associated long noncoding RNAs. Aging Cell. 2013;12:890-900.

44. Kommoju U, Samy S, Maruda J, Irgam K, Kotla J, Velaga L, Reddy B. Association of CDKAL1, CDKN2A/B \& HHEX gene polymorphisms with type 2 diabetes mellitus in the population of Hyderabad, India. Indian J Med Res. 2016:143:455-63.

45. Chidambaram M, Radha V, Mohan V. Replication of recently described type 2 diabetes gene variants in a South Indian population. Metabolism. 2010;59: 1760-6

46. Degirmenci U, Lei S. Role of IncRNAs in cellular aging. Front Endocrinol. 2016;7:151.
47. Palmer AK, Tchkonia T, LeBrasseur NK, Chini EN, Xu M, Kirkland JL. Cellular senescence in type 2 diabetes: a therapeutic opportunity. Diabetes. 2015;64: 2289-98.

48. Prattichizzo F, Nigris V, Sala L, Procopio A, Olivieri F, Ceriello A. "Inflammaging" as a druggable target: a senescence-associated secretory phenotype-centered view of type 2 diabetes. Oxidative Med Cell Longev. 2016;2016:1810327.

49. Sathishkumar C, Prabu P, Balakumar M, Lenin R, Prabhu D, Anjana R, Mohan V, Balasubramanyam M. Augmentation of histone deacetylase 3 (HDAC3) epigenetic signature at the interface of proinflammation and insulin resistance in patients with type 2 diabetes. Clin Epigenetics. 2016:8:125.

50. Han P, Chang C-P. Long non-coding RNA and chromatin remodeling. RNA Biol. 2015;12:1094-8

51. Wang H, Liang Y, Li Y. Non-coding RNAs in exercise. Non-coding RNA Investigation. 2017:1:10. https://doi.org/10.21037/ncri.2017.09.01.

52. Anderson DM, Anderson KM, Chang C-L, Makarewich CA, Nelson BR, McAnally JR, Kasaragod P, Shelton JM, Liou J, Bassel-Duby R, et al. A micropeptide encoded by a putative long noncoding RNA regulates muscle performance. Cell. 2015;160:595-606.

53. Beaver LM, Kuintzle R, Buchanan A, Wiley MW, Glasser ST, Wong CP, Johnson GS, Chang JH, Löhr CV, Williams DE, et al. Long noncoding RNAs and sulforaphane: a target for chemoprevention and suppression of prostate cancer. J Nutr Biochem. 2017:42:72-83.

54. Zhang F, Gao C, Ma XF, Peng XL, Zhang RX, Kong DX, Simard AR, Hao JW. Expression profile of long noncoding RNAs in peripheral blood mononuclear cells from multiple sclerosis patients. CNS Neurosci Ther. 2016; 22:298-305.

55. Vausort M, Wagner DR, Devaux Y. Long noncoding RNAs in patients with acute myocardial infarction. Circ Res. 2014;115:668-77.

56. Yuan M, Wang S, Yu L, Qu B, Xu L, Liu L, Sun H, Li C, Shi Y, Liu H. Long noncoding RNA profiling revealed differentially expressed IncRNAs associated with disease activity in PBMCs from patients with rheumatoid arthritis. PLoS One. 2017;12:e0186795.

57. Zhang H, Xue C, Wang Y, Shi J, Zhang X, Li W, Nunez S, Foulkes AS, Lin J, Hinkle CC, Yang W, Morrisey EE, Rader DJ, Li M, Reilly MP. Deep RNA sequencing uncovers a repertoire of human macrophage long intergenic noncoding RNAs modulated by macrophage activation and associated with cardiometabolic diseases. J Am Heart Assoc. 2017;6. https://doi.org/10.1161/ JAHA.117.007431.

\section{Ready to submit your research? Choose BMC and benefit from:}

- fast, convenient online submission

- thorough peer review by experienced researchers in your field

- rapid publication on acceptance

- support for research data, including large and complex data types

- gold Open Access which fosters wider collaboration and increased citations

- maximum visibility for your research: over $100 \mathrm{M}$ website views per year

At $\mathrm{BMC}$, research is always in progress.

Learn more biomedcentral.com/submissions 